\title{
Processo de internacionalização da empresa Rota do Mar
}

\section{Internationalization Process of Rota do Mar Company}

\author{
Rennaly Alves da Silva ${ }^{1}$ \\ Walter Fernando Araújo de Moraes $^{2}$
}

\section{Resumo}

Com o aumento da competição, a atuação das empresas tem se tornado cada vez menos limitada aos mercados nacionais. Nesse contexto, o processo de internacionalização emerge como tema central nos estudos de estratégia. Assim, o presente estudo tem o objetivo de compreender como ocorre o processo de internacionalização da Rota do Mar, empresa localizada no polo de confecções de Santa Cruz do Capibaribe, em Pernambuco. A escolha pela empresa ocorreu em função da sua representatividade não só para o Estado, por ser a maior empresa de confecções, mas também para a região Nordeste. Utiliza-se o modelo de Uppsala, abrangendo a sua evolução ao longo de quase quatro décadas. $\mathrm{Na}$ pesquisa, é utilizada a metodologia qualitativa e a estratégia de estudo de caso, com perspectiva de processo. A análise da empresa permitiu identificar nove evidências complementares ao modelo de Uppsala acerca das características do processo de internacionalização. Aspectos tais como o papel do agente externo de exportação, do conhecimento experiencial, da atuação da empresa no mercado doméstico e da escolha do mercado de atuação, mostraram-se relevantes para este processo.

Palavras-chave: Processo deinternacionalização. Modelo de Uppsala. Polo de confecções. Exportação. Importação.

\section{Abstract}

With increasing competition, the performance of companies has become less and less confined to national markets. In this context, the process of internationalization

Doutoranda pelo PPGA da Universidade Federal de Pernambuco (PROPAD/UFPE). Afiliação: Universidade Federal da Paraíba - UFPB. Brasil. Lattes: http://lattes.cnpq.br/3203964444352889 Email: rennaly@hotmail.com

2 Pós-Doutorado - University of Texas at Austin. Afiliação: Universidade Federal de Pernambuco - UFPE. Brasil. Lattes: http://lattes.cnpq.br/6093921820124337 Email: walter.moraes@ufpe.br 
emerges as the central theme of the strategy studies. Thus, this study aims to understand how occurs the internationalization process of the Rota do Mar, a company located in Clothing Polo of Santa Cruz do Capibaribe in Pernambuco. The choice by the company was due to its representation not only to the state, to be the largest clothing company, but also for the Northeast region. It's used the Uppsala Model, including its evolution over nearly four decades. In the survey, it's used qualitative methodology and case study strategy with process perspective. The company's analysis identified nine additional evidence to Uppsala Model about the characteristics of its internationalization process. Aspects such as the role of foreign export agent, the experiential knowledge, the company's performance in the domestic market, and the choice of market segment were relevant to this process.

Keywords: Internationalization Process. Uppsala Model. Clothing Polo. Export. Import.

\section{Introdução}

A competição entre empresas rapidamente se expandiu, e continua a se ampliar dos mercados domésticos aos mercados internacionais (ALEM; CAVALCANTI, 2005; FREITAS;RUPOLO; OLIVEIRA, 2015). Nesse sentido, a estratégia de internacionalização poderia ser considerada um tipo de estratégia de diversificação (BARNEY, 2011). No entanto, evidências apresentadas por estudos empíricos indicam que as teorias e as práticas desenvolvidas para o mercado doméstico podem não se aplicar à realidade das empresas que atuam em mercados externos (KOVACS; MORAES, 2005; MCDOUGALL, 1989).

Dentre as abordagens que buscam explicar a internacionalização das empresas, a comportamental explica que a internacionalização ocorre de forma incremental, com o comprometimento crescente dos recursos. De acordo com esse entendimento, duas vertentes recebem destaque (ANDERSEN, 1993): o I-Model (CAVUSGIL,1984); e o U-Model, ou modelo de Uppsala (JOHANSON; VAHLNE, 1977). Essas duas vertentes apresentam aspectos muito semelhantes. Ambas valorizam o conhecimento experiencial como um fator importante no processo de internacionalização, abordando a questão da incerteza e o incrementalismo. Contudo, uma das principais diferenças entre os 
modelos está no fato do I-Model parecer mais adequado às pequenas empresas, enquanto o U-Model seria para empresas de qualquer tamanho (ERIKSSON; JOHANSON; MAJKGARD, 1997). Como o estudo analisa uma empresa de porte médio, há a escolha pelo U-Model ou modelo de Uppsala.

O modelo de Uppsala discute o gradualismo como uma forma de mitigar os efeitos da incerteza e de melhorar a percepção sobre os riscos em decorrência do aumento do conhecimento pela experiência (JOHANSON; VAHLNE, 1977; JOHANSON; WIEDERSHEIM-PAUL, 1975). Posteriormente, a abordagem evolui no reconhecimento da influência das relações duais (JOHANSON; VAHLNE, 1990), triádicas (HAVILA;JOHANSON;THILENIUS, 2004), da rede de negócios (HOLM; ERIKSSON; JOHANSON, 1996; 1999; JOHANSON; VAHLNE, 2003; 2006; 2009; SHARMA; JOHANSON, 1987) e, finalmente, na identificação do papel desempenhado pelo empreendedor para o processo de internacionalização (SCHWEIZER; VAHLNE; JOHANSON, 2010).

Para a realização desta pesquisa, escolheu-se o polo de confecções de Santa Cruz do Capibaribe em função da sua representatividade não só para o estado de Pernambuco, mas também para a região Nordeste. O Estado concentra cerca de $20 \%$ das indústrias de confecções nordestinas e $2,6 \%$ das indústrias brasileiras (IBGE, 2015). O Polo de Confecções do Agreste, formado pelos municípios de Caruaru, Toritama e Santa Cruz do Capibaribe, segundo o Sebrae (2013), apresenta um faturamento anual bruto próximo de $\mathrm{R} \$ 1$ bilhão. A empresa Rota do Mar, pertencente a este polo, é a maior empresa de confecções do estado de Pernambuco (VEJA, 2016).

Desse modo, emerge a seguinte pergunta de pesquisa: Quais as características do processo de internacionalização da empresa Rota do Mar? Por conseguinte, o artigo tem o objetivo de compreender as características do processo de internacionalização da Rota do Mar, empresa localizada no polo de confecções de Santa Cruz do Capibaribe, em Pernambuco. 
Apesar da sua relevância, o polo de confecções de Santa Cruz do Capibaribe é conhecido por produzir peças de baixa qualidade (BARROS, 2009). Apenas $0,7 \%$ da criação é realizada por estilistas próprios (MARTINS; ANDRADE; CANDIDO, 2009). Apesar das barreiras protecionistas, as empresas que fazem parte do polo têm sentido os efeitos do aumento da concorrência, sobretudo oriunda da China (BARROS, 2009). Mesmo com essas limitações, tem-se percebido o movimento de algumas empresas da região em direção aos mercados internacionais. Segundo dados do Ministério do Desenvolvimento, Indústria e Comércio Exterior (MDIC, 2016), 19 (dezenove) empresas de confecções de Santa Cruz do Capibaribe realizaram atividade de exportação entre os anos de 2001 a 2015.

A relevância do presente estudo reside na ausência de trabalhos que abordem a evolução do modelo de Uppsala ao longo das quatro décadas em que os autores publicaram modificações, de modo a torná-lo mais adequado às novas dinâmicas de mercado e a incorporar as temáticas que surgiam na literatura e que pudessem auxiliar na compreensão. Mesmo que o modelo seja ainda o mais citado no Journal International Business, as referências são feitas à sua primeira publicação (JOHANSON; VAHLNE, 1977). Além disso, busca-se identificar se estas alterações no modelo ou nos seus pressupostos são suficientes para torna-lo capaz de explicar o comportamento da empresa no seu processo de internacionalização, considerando as inúmeras críticas que vem recebendo ao longo dos anos.

\section{Fundamentação teórica}

\subsection{Abordagem Comportamental de Internacionalização}

Duas vertentes da abordagem comportamental dos estudos sobre negócios internacionais recebem destaque (ANDERSEN, 1993): o I-Model, que apresenta a internacionalização como uma forma da empresa inovar (CAVUSGIL,1984); e o U-Model, ou modelo de Uppsala, 
em que a decisão por atuar em determinado mercado deve considerar as distâncias psíquicas (JOHANSON; VAHLNE, 1977).

Uma das principais diferenças entre eles está no fato do I-Model ser mais adequado às pequenas empresas, enquanto o U-Model para empresas de qualquer tamanho (ERIKSSON et al., 1997). Por ser mais consolidado e mais amplo em termos acadêmicos, será adotado o modelo de Uppsala. Não obstante ser amplamente utilizado, percebese que sua aplicação geralmente se restringe à versão inicial, proposta em 1977, desconsiderando aspectos importantes apresentados pelos autores em publicações posteriores, como as de 2003, 2006, 2009 e 2010.

\subsection{Modelo de Uppsala}

Em sua origem, o modelo de Uppsala assume que o desenvolvimento das atividades e a solução de possíveis problemas exigem conhecimento sobre o funcionamento do mercado (JOHANSON; VAHLNE, 1977). Portanto, há o entendimento de que a internacionalização ocorre por meio de um processo incremental de aprendizagem, em que o gradualismo das ações em direção aos mercados internacionais implica no comprometimento crescente dos seus recursos, minimizando os efeitos da incerteza (JOHANSON; VAHLNE, 1977; JOHANSON; WIEDERSHEIM-PAUL, 1975).

Quanto mais se conhece determinado mercado, menor a incerteza e melhor a percepção sobre os riscos de atuação nesse mercado. Assim, o curso de ações em direção aos mercados internacionais é denominado cadeia de estabelecimento, de modo que, inicialmente, as atividades de exportação não são regulares. Posteriormente, com o aumento do conhecimento sobre o mercado, ocorrem as exportações através de representantes independentes (agentes), seguidas pelo estabelecimento de filiais de vendas. Por fim, pelo estabelecimento das subsidiárias de produção (JOHANSON; VAHLNE, 1977; JOHANSON; WIEDERSHEIM-PAUL, 1975). 
Em função disso, as empresas começam a exportar para países cuja distância psíquica é menor em relação ao país de origem, ou seja, cujos fatores que dificultam ou impedem o fluxo de informações de e para o mercado - como as diferenças de idioma, os padrões culturais, a estrutura do mercado - são menores (JOHANSON; VAHLNE, 1977).

Baseado nessas proposições, o modelo do processo de internacionalização é desenvolvido tendo sua estrutura principal dividida entre os aspectos referentes ao "Estado" e à "mudança". No aspecto Estado, o comprometimento de mercado é composto pela quantidade de recursos alocados para o mercado externo e pelo grau de compromisso destes recursos, ou seja, pelo custo de transferência dos recursos para outros mercados. Por sua vez, o conhecimento do mercado permite que a empresa identifique as oportunidades e ameaças, avaliando as alternativas de ação. No aspecto mudança, as atividades atuais da empresa podem ser consideradas sua principal fonte de conhecimento experiencial. Já as decisões de comprometimento serão tomadas a partir do conhecimento que se tem sobre o mercado (JOHANSON; VAHLNE, 1977).

Dessa forma, o modelo tem como base a suposição de que as empresas têm acesso limitado às informações sobre os mercados estrangeiros. Essa limitação é reduzida com o aprendizado resultante do envolvimento crescente com esses mercados (JOHANSON; VAHLNE, 1977; JOHANSON; WIEDERSHEIM-PAUL, 1975).

\subsection{Críticas e contribuições}

Desde a publicação do modelo de Uppsala, vários estudiosos se empenharam em avaliar a sua aplicabilidade (BILKEY; TESAR, 1977; CAVUSGIL, 1984; CHANG, 1995; DAVIDSON, 1980; WIEDERSHEIMPAUL; OLSEN; WELCH, 1978), verificando, inclusive, sua validade teórica (ANDERSEN, 1993; BARKEMA; BELL; PENNINGS, 1996; FORSGREN, 2002; PEDERSEN; PETERSEN, 1998), fazendo do artigo o trabalho mais citado dentre os publicados pelo Journal of International 
Business. Alguns aspectos foram confirmados, outros questionados, havendo críticas e sugestões de melhorias.

Apesar das críticas, a aplicabilidade do modelo foi comprovada em diversos estudos. Considerando que as empresas analisadas foram suecas, poderia ser esperado que sua aplicação fosse válida apenas para as empresas deste país. Contudo, estudos posteriores a confirmaram como válida em diversos países: para empresas norte-americanas (BILKEY; TESAR, 1977; CAVUSGIL, 1984; DAVIDSON, 1980; KOGUT; SINGH, 1988), australianas (WIEDERSHEIM-PAUL;OLSEN; WELCH, 1978), japonesas (CALOF; BEAMISH, 1995; CHANG, 1995), holandesas (BARKEMA; BELL; PENNINGS, 1996), brasileiras (FREITAS; RUPOLO; OLIVEIRA, 2015; HILAL; HEMAIS, 2001), entre outras. De forma geral, estes estudos empíricos apoiam o modelo, confirmando a relevância do compromisso, da experiência e das diferenças culturais para a explicação do comportamento de internacionalização (JOHANSON; VAHLNE, 1990).

Várias outras críticas direcionadas aos trabalhos conduzidos sob a liderança de Johanson (JOHANSON; VAHLNE, 1977; JOHANSON; WIEDERSHEIM-PAUL, 1975) se referem à sua limitação na capacidade de explicar como as diferenças culturais influenciam a escolha do modo de atuação (ANDERSEN, 1993; KOGUT; SINGH, 1988). Além disso, tal escolha e a mudança de um modo de atuação para outro é explicada apenas em função da obtenção de conhecimento (CALOF; BEAMISH, 1995). Ademais, assume-se que o modelo não contempla que se possa avaliar qualquer alternativa além das que estão previstas - exportação, agente externo, filiais de vendas e subsidiárias (ANDERSEN, 1993).

Entretanto, existem formas da organização adquirir conhecimento para além do "aprender fazendo", tais como a possibilidade de obter informações por meio de parceiros, da participação em redes de negócios, além da possibilidade de imitar as empresas com alta legitimidade imitar as ações adotadas por um grande número de organizações, pois o sucesso das práticas é dado como certo -, de adquirir empresas que já possuam o conhecimento necessário ou realizar joint ventures. 
Assim, as empresas poderiam investir em mercados estrangeiros sem conhecimento experiencial (FORSGREN, 2002).

Outra crítica dirigida ao modelo de Uppsala questiona o fato dele assumir o processo como sendo inevitavelmente contínuo, ou seja, não considerar a possibilidade de que a empresa pode desistir de atuar em mercados estrangeiros em qualquer uma das etapas do processo de internacionalização (ANDERSEN, 1993; WELCH; LUOSTARINEN, 1988). Além disso, alega-se que o entendimento de que a empresa aprende apenas por meio da experiência não é adequado (BUCKLEY, 1988). O conhecimento, na realidade, pode ser resultado não apenas de experiências anteriores, mas de um processo de troca entre as empresas (ANDERSON; WEITZ, 1992). As oportunidades e ameaças podem ser apresentadas por seus relacionamentos. O acesso a recursos externos, importantes para o processo de internacionalização pode ser obtido por meio da participação em redes de relacionamentos (BENITO; WELCH, 1994).

\subsection{Evolução do modelo de Uppsala}

Em trabalho posterior (JOHANSON; VAHLNE, 2006), os autores esclarecem que a interpretação dada aos seus pressupostos em diversos estudos foi equivocada. Eles explicam que o modelo não é sobre a cadeia de estabelecimento (JOHANSON; VAHLNE, 1977), mas que este foi o "fenômeno empírico observado que forneceu impulso para o seu desenvolvimento" (JOHANSON; VAHLNE, 2006. p. 166). O modelo, na realidade, se refere à interação entre a obtenção do conhecimento e o aumento de compromisso com o mercado externo (JOHANSON; VAHLNE, 2006).

Mesmo assim, os autores reconhecem que o modelo inicial (JOHANSON; VAHLNE, 1977) possui algumas limitações (JOHANSON; VAHLNE, 2003; 2006) e, em resposta às diversas críticas, a análise do processo de internacionalização é estendida sob a perspectiva dos relacionamentos. Inicialmente, as díades - relacionamento entre dois atores - são incluídas nas análises (HALLEN; JOHANSON; MOHAMED, 
1991; JOHANSON; VAHLNE, 1990; SHARMA; JOHANSON, 1987), e depois as tríades - relacionamento entre três atores, por exemplo, empresa exportadora, agente externo e empresa importadora - (HAVILA; JOHANSON; THILENIUS, 2004). Em seguida, as redes são admitidas como forma de inserção no mercado internacional (JOHANSON; VAHLNE, 2006; 2009).

As redes de relacionamentos podem ser compreendidas como um conjunto de relações formadas por atores de diferentes negócios, e possuir maior ou menor inserção internacional dependendo da extensão das suas ligações com outros países (JOHANSON; VAHLNE, 1990). Dessa forma, o processo de internacionalização depende não apenas das capacidades internas da empresa, mas também da sua posição em uma rede, ou seja, do seu envolvimento com parceiros que atuam em mercados externos. $O$ acesso a esses relacionamentos pode ter uma relevância maior do que a distância psíquica (JOHANSON; MATTSSON, 1988). Estudos indicam que a internacionalização das empresas seja resultado das vantagens obtidas por meio da inserção na rede de negócios (LINDQVIST, 1991).

Entretanto, para que uma empresa possa fazer parte de uma rede, é necessário que as demais estejam dispostas a se envolverem nessa nova interação, o que faz com que os conceitos de "conhecimento", "comprometimento", "decisões de compromisso" e "atividades atuais" deixem de ser unilaterais, como sugere o modelo inicial, e se tornem questões multilaterais (JOHANSON; VAHLNE, 1990). Esse aspecto foi negligenciado no modelo inicial (JOHANSON; VAHLNE, 1977), com a justificativa de que, na época, não havia ferramentas para que fosse mais bem desenvolvido. Posteriormente, a criação de oportunidades foi incluída na discussão (JOHANSON; VAHLNE, 2006), e no próprio modelo (JOHANSON; VAHLNE, 2009).

Desse modo, as oportunidades e ameaças com as quais se depara uma empresa em processo de internacionalização estão menos relacionadas com as especificidades do país, e mais com a forma de entrada no mercado estrangeiro. Os relacionamentos da 
rede proporcionam mais do que o aprendizado, são capazes de tornar a empresa um insider, ou seja, incluí-la na rede de negócios. Uma empresa que não tem uma posição relevante na rede é um outsider, não tendo acesso às informações importantes (JOHANSON; VAHLNE, 2009; SCHWEIZER;VAHLNE; JOHANSON, 2010).

Assim, o modelo evoluiu para que possa abranger também a perspectiva de redes de relacionamentos (JOHANSON; VAHLNE, 2009). Mais recentemente, foi incluída também a capacidade empreendedora como uma variável do modelo, partindo do entendimento de que o empresário que toma as decisões de internacionalização não o faz apenas de forma racional, mas é influenciado por características idiossincráticas, com capacidades tanto emocionais quanto intelectuais. Assim, a aprendizagem resultante da experiência seria um fator importante para essas decisões (SCHWEIZER; VAHLNE; JOHANSON, 2010).

\section{Procedimentos metodológicos}

Adota-se, na pesquisa que embasou este artigo, uma metodologia qualitativa (CRESWELL, 2010; MERRIAM, 2009). Com relação à estratégia de pesquisa, utiliza-se o estudo de caso (STAKE, 2009). Assim, a escolha do caso ocorreu em dois níveis: a escolha da empresa e a escolha dos entrevistados (FLICK, 2009; MERRIAN, 2009).

A seleção da empresa ocorreu, como forma de satisfazer o objetivo proposto, a partir do estabelecimento de duas condições: fazer parte do polo de confecções em questão e atuar (ou ter atuado) em mercados internacionais. Desse modo, considerando ainda o critério de acessibilidade (STAKE, 2009), a empresa selecionada foi a Indústria e Comércio de Confecções Xavier Ltda., que tem por nome fantasia "Rota do Mar". Com relação à escolha dos entrevistados, ocorreu de forma intencional e por conveniência (MERRIAM, 2009; PATTON, 2001). Foram entrevistados os membros da direção - responsáveis pelos processos de internacionalização das empresas - e outras pessoas que estavam 
acompanhando o processo, totalizando seis (6) entrevistas, conforme o quadro 1, entre os meses de agosto e outubro de 2012.

Quadro 1: Entrevistados, função e tempo na empresa

\begin{tabular}{|ccc|}
\hline ENTREVISTADOS & FUNÇÃO & TEMPO NA EMPRESA \\
1 & Diretor Proprietário & 16 anos \\
2 & Secretária da Diretoria & 5 anos \\
3 & Diretor Administrativo & 12 anos \\
4 & Diretor Industrial & 8 anos \\
5 & Compras de materiais & 16 anos \\
6 & Diretor Comercial & 10 anos \\
\hline
\end{tabular}

Com o intuito de permitir a compreensão da internacionalização como um processo em evolução, foi realizada uma pesquisa com abordagem longitudinal, de caráter retrospectivo, ex-post facto (MATOS; VIEIRA, 2001), no período que compreende o início das atividades nos mercados externos até o ano de 2012. Assim, a pesquisa é realizada a partir de uma perspectiva de processo, como uma série temporal de eventos críticos ou estados (MELIN, 1992; PETTIGREW, 1990; 1997). Por eventos críticos, entende-se: "fatos, situações e decisões vivenciadas e/ou tomadas pela empresa que impactaram ou desencadearam em mudanças" (SOUSA; FREITAS, 2012, p. 12) durante o processo de internacionalização.

Com relação à coleta dos dados, optou-se pela triangulação metodológica como forma de minimizar possíveis deturpações e equívocos, inclusive de interpretação (STAKE, 2009). Assim, foram utilizados três métodos: entrevistas semiestruturadas, utilização de dados visuais e pesquisa documental, conforme o quadro 2. As entrevistas foram realizadas com o auxílio de um protocolo, e gravadas com a autorização dos entrevistados (CRESWELL, 2010, p. 216). Quanto aos dados visuais, optou-se pela utilização de duas formas de obtenção: os pesquisadores produziram registros visuais ou utilizaram as imagens registradas por terceiros, que foram fornecidas pela 
empresa ou se encontravam disponíveis para livre acesso. Por fim, os documentos utilizados são, principalmente, os registros impressos ou eletrônicos produzidos pelas empresas ou por terceiros - tais como jornais e revistas.

Quadro 2: Fontes de dados da pesquisa

\begin{tabular}{|ll|}
\hline FONTES DE DADOS & DESCRIÇÃO \\
Entrevistas & Seis entrevistas realizadas com pessoas \\
& da empresa envolvidas no processo de \\
& internacionalização. \\
Pesquisa documental & Documentos impressos ou eletrônicos produzidos \\
& pela empresa ou por terceiros, disponíveis para \\
& livre acesso ou fornecidos aos pesquisadores \\
& pelos responsáveis. \\
Dados visuais & Registros visuais produzidos pelos pesquisadores \\
& ou pela empresa e fornecidos aos pesquisadores, \\
& retratando a participação da empresa em eventos \\
& relevantes para o processo de internacionalização, \\
& como feiras ou rodadas de negócios.
\end{tabular}

O protocolo utilizado envolveu orientações para a coleta de documentos e de imagens que pudessem fornecer evidências, seja para comprovar, seja para complementar, àquelas obtidas por meio das entrevistas, se reforçando mutuamente. Foi desenvolvido um roteiro de entrevista com questões que abordavam, além das informações sobre os entrevistados, os seguintes aspectos: modo de entrada, eventos críticos, oportunidades, escolha do mercado, conhecimento do mercado, modo de atuação, papel das redes de relacionamento, papel do empreendedor, comprometimento com o mercado, e ameaças e questões mais amplas que permitissem ao entrevistado discorrer sobre qualquer aspecto que julgasse relevante para o processo (MARTINS, 2008).

A análise dos dados ocorreu por meio do método de comparação constante (MERRIAM, 2009). Trata-se de um desdobramento da 
Grounded Theory, em que são realizados movimentos "de ir e vir entre pedaços concretos de dados e conceitos abstratos, entre o raciocínio indutivo e dedutivo, entre a descrição e a interpretação" (MERRIAM, 2009, p. 176). Para auxiliar o processo de análise, após a realização das transcrições, os textos, os documentos e as imagens resultantes da pesquisa de campo foram inseridos no software de análise de dados qualitativos Atlas.ti, versão 6.0, o que facilitou o processo de codificação.

Ao término da análise, a fidedignidade e validade dessas evidências foram verificadas. Nesse sentido, foi realizado o reexame de como os participantes realmente responderam e da avaliação de leitores, com a consideração de interpretações alternativas, que não as dos pesquisadores (BAUER; GASKELL, 2008).

\section{Análise dos resultados}

\subsection{Análise da empresa Rota do Mar}

A Rota do Mar foi fundada em 1996 na cidade de Santa Cruz do Capibaribe - PE. Atua no ramo de confecções, mais especificamente nos segmentos surf e streetwear - moda praia e moda urbana respectivamente. A empresa começou atuando nos fundos de uma casa e se tornou a maior empresa de confecções de Pernambuco e uma das principais do Nordeste, conforme matéria divulgada na Revista Veja (2016).

Ano após ano, a empresa cresceu de forma acelerada (SINTEX, 2012). Em decorrência, conta com o auxílio de 12 (doze) facções distribuídas por todo o Brasil. Além disso, dispõe de 13 (treze) representantes comerciais, atendendo 21 (vinte e um) estados brasileiros, e possui 5 (cinco) lojas distribuídas no polo de confecções de Pernambuco - Caruaru, Toritama e Santa Cruz do Capibaribe -, que empregam 194 colaboradores, além dos 210 funcionários que atuam na sua fábrica. Assim, estima-se que gera mais de mil empregos diretos e indiretos. 
As 5 (cinco) lojas funcionam como "atacarejos", conhecidas assim por atuarem no atacado e no varejo. Justificando a pequena quantidade de lojas, o diretor e proprietário da empresa explica que a estratégia de crescimento está pautada nas vendas aos representantes comerciais. Os investimentos em qualidade dos produtos e campanhas publicitárias, aliados aos preços competitivos praticados, têm gerado notoriedade para a empresa, o que tem resultado em convites importantes para participação em Rodadas de Negócios Internacionais, levando-a a atuar nos mercados externos. Percebe-se que a internacionalização por meio de convite não é um aspecto contemplado pelo modelo de Upssala.

\subsection{O processo de internacionalização}

A partir da comparação entre os dados obtidos por meio das entrevistas, dos documentos e das imagens, foi possível identificar, com o auxílio do software Atlas.ti, 30 códigos que agrupam informações com características comuns ou relacionadas. Posteriormente, esses códigos originaram quatro categorias, que são conjuntos mais gerais dos dados. São elas: Conhecimento de internacionalização; Acesso aos mercados externos; Países e características de exportação; e Características da importação.

Com relação à primeira categoria, "Conhecimento de internacionalização", foram identificados 3 (três) códigos: conhecimento do mercado, conhecimento do processo e estratégia deliberada. No que diz respeito à identificação destes códigos, percebeu-se que um fator importante que contribuiu para que a Rota do Mar passasse a atuar nos mercados externos foi o fato de o proprietário, já conhecer praticamente todos os países para os quais a empresa exportou. A partir desse conhecimento, ele percebeu que poderia existir demanda para seus produtos. $O$ desenvolvimento das atividades de exportação foi uma forma da empresa aprender sobre os processos necessários, além de servir para que se pudesse avaliar a sua capacidade de atender aos mercados internacionais. Assim, entende-se que a decisão por iniciar o processo de internacionalização da empresa foi parte de uma estratégia 
deliberada, e não apenas decorrente do surgimento das oportunidades, conforme evidenciado no depoimento:

Bem, a intenção nossa era de entender o processo. Era conhecer como era o processo de exportação [...] para, à medida com que a empresa crescesse, tivesse o momento de exportar, a gente não estivesse tão leigo na hora [...]. Esse foi mais o interesse. Não era tanto de lucratividade, mas de conhecimento mesmo. (ENTREVISTADO 1; 1:15; 8:8).

Quanto à segunda categoria, "Acesso aos mercados externos", foram identificados 8 (oito) códigos: órgãos de apoio; desempenho no mercado local; feiras/rodadas de negócios internacionais; agente de exportação; rede de relacionamento; distância cultural; oportunidade; e escolha do mercado. No que se refere à identificação dos códigos, percebeu-se que, pelo fato da Rota do Mar ter obtido nos últimos anos um desempenho superior com relação às empresas locais, os órgãos de apoio, como o SEBRAE, passaram a convidar a empresa para as feiras e rodadas de negócios internacionais. A partir da participação nessas rodadas, o contato estabelecido com os agentes independentes de exportação (definidos, para fins desse trabalho, como aqueles que intermedeiam as exportações da empresa doméstica com os mercados externos) facilitou a entrada da empresa nos mercados externos, reduzindo a necessidade de conhecimento sobre estes mercados. Assim, não houve escolha deliberada pelos mercados de atuação, mas eles surgiram como oportunidades de negócios proporcionadas pelos agentes.

No que se refere à terceira categoria, "Países e características de exportação", foram identificados 5 (cinco) códigos: exportação para Portugal, exportação para Espanha, exportação para a África, modo de exportação, e mercado local x mercado externo. A Rota do Mar participou de uma rodada de negócios internacional que ocorreu em Fortaleza - CE, no ano de 2004. Nessa rodada, um representante se interessou pelos produtos e levou um mostruário para Portugal, o que resultou na primeira exportação da empresa. Logo na semana seguinte, 
uma empresa que atua no mesmo segmento que a Rota do Mar, mas em Portugal, estava precisando terceirizar parte da sua produção e procurou a empresa por indicação de um ex-funcionário. No mesmo ano, a Rota do Mar passou a produzir as peças.

Ainda exportando para Portugal, a empresa participou, em 2005, da Semana Internacional de Moda de Madri - SIMM. Nessa rodada de negócios, o representante que vendia os produtos da Rota do Mar em Portugal levou outro agente de exportação para conhecer o stand da empresa. Ele se interessou pelos produtos e começou a vendêlos na Espanha. No ano seguinte, a partir de mais uma indicação, um representante de uma trade atuante nos países africanos visitou a fábrica da Rota do Mar para conhecer os produtos e os levou para vender em Angola. Em todos os casos, não houve exportação direta, mas por meio de agente de exportação.

A empresa continuou exportando para Portugal, Espanha e África até 2006. Desde então, entretanto, a Rota do Mar não exporta mais para nenhum país. Isso ocorreu porque a demanda no mercado local estava cada vez maior, sendo capaz de absorver toda a produção. Além disso, o mercado externo se mostrou mais exigente do que o mercado local, havendo o risco de prejudicar a marca em tais mercados se a empresa não estivesse totalmente preparada para atendê-los. Desse modo, tendo obtido o conhecimento que pretendia, a Rota do Mar optou por atender ao mercado interno e se fortalecer neste mercado, como evidenciado no depoimento:

Paramos por aí, porque a gente deu preferência para o mercado interno, que estava absorvendo toda a produção. E o mercado lá fora é um pouco exigente, tem prazo e tudo e a gente estava correndo o risco de não atender e se queimar. 2:23(ENTREVISTADO 1; 26:26)

Contudo, em visita realizada pelos pesquisadores à $14^{\mathrm{a}}$ Rodada de Negócios da Moda Pernambucana, em Caruaru, em 2012, foi possível perceber que a Rota do Mar continua sinalizando para os clientes, por meio de anúncio no seu stand, a sua intenção de exportar. 
Com relação à quarta categoria, "Características da importação", que diz respeito ao comportamento da empresa no processo de importação, foram identificados 4 (quatro) códigos: importação, escolha do mercado, rede de relacionamentos e agente de importação. Os motivos da empresa para realizar as exportações e as importações foram diferentes. Como evidenciado na categoria "Conhecimento de internacionalização", o que levou a empresa a exportar foi a necessidade de adquirir conhecimento sobre os processos. Entretanto, o que levou a empresa a importar foi a necessidade de terceirizar a fabricação de alguns produtos. Isso fez com que, diferente das exportações, houvesse a escolha do mercado em função dos preços, mesmo sendo o que possuía maior distância psíquica com relação ao mercado doméstico. Tal escolha foi também influenciada pelas indicações que a empresa recebeu por parte da sua rede de relacionamentos - empresas locais que já importavam produtos chineses e afirmavam ter um bom resultado. Feita a escolha, antes de começar a importar, o proprietário da Rota do Mar, para obter conhecimento sobre o mercado, participou como visitante de uma feira realizada em Cantão, em 2010, onde conheceu alguns fornecedores chineses por intermédio de um agente de importação. Mesmo assim, houve dificuldades com relação à distância cultural, como demonstra o seguinte depoimento:

Teve um pouco [de dificuldade]... Idioma nem tanto porque tem uma pessoa, né, que ajuda a gente... Mais por uma questão cultural mesmo. Questão de horário, né, o fuso horário [...] Tem que tá ligando de madrugada, e... Cores também, porque eles têm costume com cores, superstição com cores, aí tem que informar direitinho... E eles são muito organizados, assim, então tudo que você mandar eles fazem. Tudo. O que eles verem, o que você mandar, eles vão fazer igual aquilo ali. Se, por exemplo, sem querer você sujou aqui com alguma coisa, eles fazem a mesma sujeirinha. Dão um jeito e fazem. (ENTREVISTADO 2) 4:14 (22:22) 


\subsection{Análiseà Luz da Abordagem Teórica}

A Rota do Mar exportou entre os anos de 2004 e 2006 e, mais recentemente, desde 2010, começou a importar. Assim, percebe-se que a empresa interrompeu, durante quatro anos, as suas atividades de internacionalização. Além disso, vivenciou quatro eventos causadores de mudança no processo, que foram: 1) a participação na rodada de negócios em Fortaleza - CE, em 2004; 2) a indicação feita pelo exdesign da Rota do Mar, no mesmo ano, que resultou na parceria com uma empresa portuguesa; 3) a decisão por cessar as atividades de exportação, em 2006; e, por último, 4) a participação na Feira de Cantão, na China, no ano de 2010. Todos estes eventos também são ressaltados na figura 2.

Figura 2: Eventos críticos para o processo de internacionalização da empresa

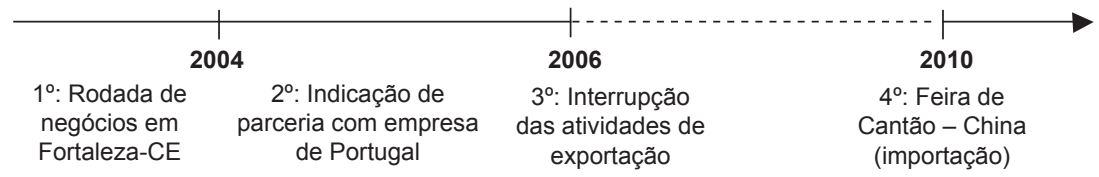

Fonte: Dados da pesquisa (2012)

O primeiro evento crítico para o processo de internacionalização da empresa ocorreu em 2004. Os órgãos de apoio locais se mostravam bastante atuantes na promoção de rodadas de negócios internacioanis e na inclusão das empresas locais em eventos realizados por todo o Brasil e no exterior, de modo que a primeira experiência de exportação da Rota do Mar ocorreu em função da sua participação em uma rodada de negócios realizada em Fortaleza, Ceará. Em decorrência, não houve escolha pelo mercado de atuação, mas este surgiu como uma oportunidade de negócios que foi apresentada à empresa pelos agentes de exportação que se encontravam na rodada. Desse modo, evidenciase que: Evidência 1 - A empresa começa a atuar nos mercados externos por intermédio de agentes externos independentes. 
Esta evidência contraria o que sugere a versão inicial do modelo de Uppsala ao afimar que as empresas escolhem exportar para países dos quais já possuam conhecimento ou com que tenham menor distância psíquica com relação ao país de origem (JOHANSON; VAHLNE, 1977). Por outro lado, corrobora o que defendem os autores em uma das suas publicações mais recentes, em que se espera que a escolha dos mercados seja influenciada pelas oportunidades apresentadas à empresa por sua rede de relacionamentos (JOHANSON; VAHLNE, 2009). Nesse sentido, as dificuldades impostas pela ausência de conhecimento podem ser superadas, no momento de escolha do mercado, pela participação do agente de exportação, que intermediou as negociações, o que sugere que: Evidência 2 - A necessidade de conhecimento para a escolha do mercado pode ser substituída pelo conhecimento dos agentes de exportação.

Percebe-se ainda que, antes de começar a atuar em outros países, a empresa já atuava em outros estados do próprio país, como sugerem estudos anteriores (WIEDERSHEIM-PAUL; OLSEN; WELCH, 1978). Isso indica que a escolha pelo modo de entrada no mercado pode ter sido influenciada pelas experiências interestaduais da empresa de modo que: Evidência 3 - A empresa, antes de começar a atuar em outros países, atuava em outros estados do próprio país.

Nessa perspectiva, tendo sido evidenciado que a empresa começou atuando por intermédio de agentes de exportação e que as experiências nos mercados locais podem exercer influência sobre o seu modo de atuação nos mercados externos, percebe-se que as atuações interestaduais da empresa se restringiam aos representantes de vendas ou clientes que revendiam os produtos em outros estados, não havendo subsidiárias de vendas ou de produção instaladas em qualquer estado exceto Pernambuco. Isso indica que a empresa pode ter estendido o seu modo de atuação nos mercados locais para os mercados externos, o que sugere que: Evidência 4 - O modo de atuação interestadual pode influenciar a escolha pelo modo de entrada em outros países. 
Além disso, outro aspecto importante para o processo de internacionalização, de acordo com o modelo de Uppsala (JOHANSON; VAHLNE, 1977), é a distância psíquica do país de exportação com relação ao mercado local. A Rota do Mar conitnuou exportando para Portugal, inclusive envolvendo-se mais com o mercado - quando começou a terceirizar os produtos da empresa portuguesa -, o que pode indicar que a distância psíquica, de fato, exerce influência sobre a possibilidade de envolvimento da empresa com os marcados externos, embora não tenha exercido impacto na escolha dos mercados. Assim: Evidência 5 - A distância psíquica exerce influência sobre a continuidade de atuação da empresa no mercado externo.

Isso ocorre, especialmente, quando as dificuldades impostas pela distância psíquica são superadas por intermédio da atuação dos agentes de exportação ou pela contribuição das redes de relacionamentos, que são capazes de inserir a empresa nos mercados externos e de facilitar o fluxo de informações entre os mercados (JOHANSON; VAHLNE, 2009). Não obstante, sabe-se que a empresa já conhecia Portugal antes de iniciar as atividades de exportação para aquele mercado e que, em função deste conhecimento prévio, conseguiu se manter atuando no país, o que indica que: Evidência 6 - O conhecimento prévio sobre os mercados externos pode facilitar a continuidade de atuação da empresa nestes mercados.

A influência das redes de relacionamentos é mais evidente no segundo evento crítico para o processo de internacionalização da empresa. Quanto a este evento, diversas características foram identificadas: a distância psíquica entre os mercados são consideradas baixas (JOHANSON; VAHLNE, 1977); a empresa possuía conhecimento sobre os processos de exportação (JOHANSON; VAHLNE, 1977; 2009; SCHWEIZER; VAHLNE; JOHANSON,2010); não houve influência direta do empreendedor (SCHWEIZER; VAHLNE; JOHANSON,2010), mas a exportação ocorreu a partir do surgimento de oportunidades de exportação (JOHANSON; VAHLNE, 2009); e, mais uma vez, não houve escolha pelos mercados de atuação, mas este surgiu em função do conhecimento que os agentes externos possuíam sobre os mesmos. 
Esta última característica indica que a falta de conhecimento novamente pôde ser compensada por meio da atuação dos agentes de exportação.

A principal diferença com relação ao primeiro evento crítico é que, no segundo, as oportunidades de exportação ocorreram em função da influência das redes de relacionamentos - compreendidas como um sistema de relações sociais e industriais entre clientes, fornecedores, concorrentes, familiares e amigos (COVIELLO; MUNRO, 1997; JOHANSON; VAHLNE, 2006; 2009). No caso da Rota do Mar, de um exfuncionário que havia se mudado para Portugal. O agente de exportação serviu apenas como um facilitador do contato entre a empresa e o seu cliente, fazendo com que a relação entre a empresa pudesse ser estabelecida e mantida independente da permanência ou não do agente de exportação, o que caracteriza uma tríade (HAVILA; JOHANSON; THILENIUS, 2004) e demonstra que: Evidência 7 - A atuação nos mercados externos por intermédio dos agentes de exportação, que caracterizam uma tríade, pode tornar as relações da empresa com estes mercados menos dependentes dos agentes.

Assim, esses dois eventos críticos foram considerados os mais importantes para as mudanças ocorridas nas suas atividades de exportação. Contudo, em 2006, a Rota do Mar resolveu encerrar suas atividades de exportação, o que caracteriza o terceiro evento crítico. Contrariando todas as lógicas subjecentes ao modelo de Uppsala (JOHANSON; VAHLNE, 1977; 2009), pois a Rota do Mar apresentava todas as características propícias para dar continuidade ao seu processo de internacionalização, inclusive, para evoluir na cadeia de estabelecimento, passando da atuação por meio dos agentes independentes para a atuação por intermédio de subsidiária de vendas (JOHANSON; VAHLNE, 1977), entretanto, a empresa preferiu interromper suas atividades de exportação. Como justificativa, aponta o cumprimento da sua estratégia: se preparar para atuar nos mercados externos apenas quando estiver totalmente fortalecida no mercado local.

Inicialmente, o seu objetivo era obter conhecimento sobre os processos de exportação para não estar leiga no momento em que estas 
atividades pudessem se tornar imprescindíveis para a manutenção do seu desempenho, tendo em vista que havia um movimento das empresas locais para os mercados externos incentivado pelos agentes de apoio. Contudo, quando adquiriu o conhecimento que necessitava, a Rota do Mar percebeu que a atuação nos mercados externos impedia a execução da sua estratégia para o mercado local: se fortalecer e expandir a marca no Brasil. Isso fez com que a empresa decidisse interromper a sua atuação naqueles mercados. Tal comportamento indica que os aspectos internos, como a estratégia da empresa e suas capacidades, podem influenciar igualmente o processo de internacionalização da empresa, conforme evidenciado por diversos críticos ao modelo de Uppsala (CALOF; BEAMISH, 1995; WELCH; LUOSTARINEN, 1988). Assim, percebe-se que: Evidência 8 - Os aspectos internos podem influenciar o processo de internacionalização da empresa tanto quanto os aspectos externos.

Porfim, oúltimo evento crítico para o processo de internacionalização da empresa é a sua participação na Feira de Cantão, na China, em 2010. A Rota do Mar interrompeu suas atividades de exportação em 2006 e, em 2010, retomou o processo, mas, ao invés de exportar, a empresa começou a importar da China.

Esse evento apresenta características semelhantes àquelas já identifcadas nos eventos da empresa que se referem às exportações, como a existência de conhecimento sobre os processos, a influência das redes de relacionamento (JOHANSON; VAHLNE, 2009), o modo de entrada no mercado (JOHANSON; VAHLNE, 1977) e o papel do empreendedor (SCHWEIZER; VAHLNE; JOHANSON, 2010). Contudo, outras características distinguem esse dos demais eventos críticos, como a ausência de conhecimento sobre o mercado chinês, a própria escolha pelo mercado e a elevada distância psíquica (JOHANSON; VAHLNE, 1977).

Estas três características se apresentam de forma relacionada, pois, embora a empresa não conhecesse o mercado chinês e mesmo que esse mercado apresentasse elevada distância psíquica com relação 
ao país de origem, a empresa o escolheu levando em consideração os baixos preços praticados pelos fornecedores chineses. Esse comportamento refuta a premissa do modelo de Uppsala de que a empresa escolhe os mercados em função do conhecimento que possuem sobre os mesmos ou em decorrência da distância psíquica existente (JOHANSON; VAHLNE, 1977). Assim, ao invés de buscar aumentar o seu comprometimento com os mercados que já conhecia, a empresa buscou um novo mercado, desconhecido e distante psiquicamente, para dar continuidade ao seu processo de internacionalização.

Nesse sentido, percebe-se que a empresa não considerou esses aspectos, apresentados como exclusivos no modelo de Uppsala, mas apenas os benefícios de preço proporcionados pela escolha. As elevadas diferenças culturais, de idioma e com relação à forma de fazer negócios, por exemplo, puderam ser superadas com o auxílio dos agentes de importação - Evidência 1. Outro aspecto importante para que houvesse a escolha por um mercado tão distante psíquicamente, foi o fato de a empresa já estar familiarizada com os processos de exportação, possuíndo conhecimentos sobre transações internacionais. Isso significa que: Evidência 9 - O conhecimento sobre os processos (trâmites de exportação) pode ser mais importante do que o conhecimento sobre os mercados para a escolha do mercado de atuação.

Todas as evidências identificadas são sintetizadas no quadro 3, que também apresenta os principais trabalhos relacionados:

Quadro 3: Evidências obtidas com a análise dos resultados

\begin{tabular}{|l|l|}
\hline EVIDÊNCIAS SOBRE O PROCESSO DE INTERNACIONALIZAÇÃO \\
\hline EVIDÊNCIAS & $\begin{array}{l}\text { PRINCIPAIS } \\
\text { RELACIONADOS }\end{array}$ \\
\hline $\begin{array}{l}\text { Evidência 1: A empresa começa a atuar nos } \\
\text { mercados externos por intermédio de agentes } \\
\text { externos independentes. }\end{array}$ & $\begin{array}{l}\text { Johanson e Vahlne, 2009; } \\
\text { Wiedersheim-Paul, Olsen e Welch, } \\
1978\end{array}$ \\
\hline $\begin{array}{l}\text { Evidência 2: A necessidade de conhecimento para } \\
\text { a escolha do mercado pode ser substituída pelo } \\
\text { conhecimento dos agentes de exportação. }\end{array}$ & $\begin{array}{l}\text { Johanson e Vahlne, 2009; } \\
1978\end{array}$ \\
\hline
\end{tabular}




\begin{tabular}{|l|l|}
\hline $\begin{array}{l}\text { Evidência 3: A empresa, antes de começar a atuar } \\
\text { em outros países, atuava em outros estados do } \\
\text { próprio país. }\end{array}$ & $\begin{array}{l}\text { Wiedersheim-Paul, Olsen e Welch, } \\
1978\end{array}$ \\
\hline $\begin{array}{l}\text { Evidência 4: O modo de atuação interestadual pode } \\
\text { influenciar a escolha pelo modo de entrada em outros } \\
\text { países. }\end{array}$ & $\begin{array}{l}\text { Beamish e Banks, 1987; Hittet. al., } \\
2006 ; \text { Johanson e Vahlne, 2009; } \\
\text { Madhok, 1995 }\end{array}$ \\
\hline $\begin{array}{l}\text { Evidência 5: A distância psíquica exerce influência } \\
\text { sobre a continuidade de atuação da empresa no } \\
\text { mercado externo. }\end{array}$ & $\begin{array}{l}\text { Andersen, 1993; Johanson e } \\
\text { Vahlne, 1977; Welch e Luostarinen, } \\
1988\end{array}$ \\
\hline $\begin{array}{l}\text { Evidência 6: O conhecimento prévio sobre os } \\
\text { mercados externos pode facilitar a continuidade de } \\
\text { atuação da empresa nestes mercados. }\end{array}$ & $\begin{array}{l}\text { Johanson e Vahlne, 2009; Welch e } \\
\text { Luostarinen, 1988 }\end{array}$ \\
\hline $\begin{array}{l}\text { Evidência 7: A atuação nos mercados externos } \\
\text { por intermédio dos agentes de exportação, que } \\
\text { caracterizam uma tríade, pode tornar as relações da } \\
\text { empresa com estes mercados menos dependentes } \\
\text { dos agentes. }\end{array}$ & $\begin{array}{l}\text { Havila, Johanson e Thilenius, 2004; } \\
\text { Johanson e Vahlne, 2009 }\end{array}$ \\
\hline $\begin{array}{l}\text { Evidência 8: Os aspectos internos podem influenciar } \\
\text { o processo de internacionalização da empresa tanto } \\
\text { quanto os aspectos externos. }\end{array}$ & $\begin{array}{l}\text { Schweizer, Vahlne e Johanson, } \\
2010 ; \text { Welch e Luostarinen, 1988 }\end{array}$ \\
\hline $\begin{array}{l}\text { Evidência 9: O conhecimento sobre os processos } \\
\text { (trâmites de exportação) pode ser mais importante } \\
\text { do que o conhecimento sobre os mercados para a } \\
\text { escolha do mercado de atuação. }\end{array}$ & \begin{tabular}{l} 
Erikssonet al., 1997 \\
\hline
\end{tabular} \\
\hline
\end{tabular}

As evidências indicam que a empresa apresenta alguns padrões de comportamento que se mostram complementares às premissas do modelo de Upssala nos vários estágios da sua evolução, abordando também aspectos apresentados pelos críticos que contribuíram para que tal evolução ocorresse. Percebe-se que aspectos evidenciados como relevantes no estudo, como o papel da tríade e das capacidades internas, não haviam sido abordados no modelo inicial (JOHANSON; VAHLNE, 1977), mas os autores inseriram posteriormente essas temáticas na discusssão em função das críticas recebidas. Outros aspectos permanecem pouco explorados pelos autores do modelo, mesmo sendo aposntado pelos críticos, como a influência da experiência da empresa no mercado nacional para a sua atuação internacional e a 
possibilidade de diminuição do comprometimento mesmo em condições apresentadas como favoráveis pelo modelo.

\section{Conclusão}

O objetivo deste artigo foi compreender as características do processo de internacionalização da Rota do Mar, empresa localizada no polo de confecções de Santa Cruz do Capibaribe, em Pernambuco. As evidências a partir do comportamento de internacionalização da empresa indicam que o modelo de Uppsala, mesmo considerando as várias alterações realizadas pelos seus idealizadores nas últimas quatro décadas, ainda não é capaz de explicar alguns aspectos que se mostraram relevantes acerca dos passos da empresa na exploração dos mercados internacionais.

As evidências 1, 2 e 7 destacam a importância da atuação dos agentes externos de exportação. O papel destes agentes envolve a identificação da oportunidade internacional, o seu potencial para substituir a necessidade de conhecimento na escolha dos mercados externos e a sua função no relacionamento entre a empresa exportadora e importadores. Nesse sentido, a atuação dos agentes se apresenta como uma questão significativa, estando relacionada não apenas à noção de cadeia de estabelecimento, mas explicando, além da diminuição da necessidade de conhecimento, aspectos do comportamento posterior a entrada nos mercados externos.

As evidências 5 e 6 indicam que a continuidade da atuação nos mercados internacionais pode estar relacionada à distância psíquica ou ao conhecimento que a empresa tem sobre estes mercados. Percebese que o aumento do conhecimento pode reduzir os efeitos da distância psíquica sobre o processo de internacionalização. Além dessa influência ser refletida na escolha dos mercados ou do modo de atuação, como se discute na literatura, as evidências sugerem que também pode fazer com que a empresa continue ou não atuando nestes mercados. Ressalta-se que as decisões iniciais referentes ao processo de internacionalização 
não apresentaram associação com conhecimento e distância psíquica, pois foram intermediadas por agentes externos.

O comportamento da empresa dentro do mercado nacional também parece exercer influência no seu comportamento nos mercados internacionais, como indicam as evidências 3 e 4 . Percebe-se que o modo de atuação da empresa no mercado nacional se assemelhou ao comportamento de internacionalização. Além disso, as evidências 8 e 9 revelam que aspectos internos da empresa, como o seu direcionamento estratégico e o seu conhecimento sobre os trâmites necessários para exportação, também influenciaram o processo de internacionalização.

Uma questão que merece maior atenção diz respeito à ausência de escolha dos mercados externos de atuação na maior parte dos casos. Mesmo havendo conhecimento sobre os mercados e baixa distância psíquica, a empresa começou a atuar por meio de convites para exportação, especialmente resultantes da ação de agentes externos independentes. Ademais, no único caso em que houve escolha pelo mercado externo, este apresentou elevada distância psíquica com relação ao país de origem da empresa, que também não possuía nenhum conhecimento sobre o mesmo.

Outro aspecto percebido no comportamento da empresa envolve a redução do comprometimento com os mercados, ou seja, a interrupção das exportações, ainda que houvesse aumento do conhecimento. Mesmo após adquirir conhecimento sobre os mercados externos, a empresa não aumentou o seu comprometimento com os mesmos ou modificou a sua forma de atuação. Este comportamento está fora do campo explicativo do modelo, envolvendo as decisões estratégicas da empresa, área que parece pouco explorada na abordagem em questão.

Para pesquisas futuras, sugere-se a realização de estudos com empresas que se apresentem em diferentes estágios da cadeia de estabelecimento, além de identificar o que faz com que as empresas mudem de estágio na cadeia de estabelecimento, considerando as críticas que foram direcionadas ao modelo nessa perspectiva. Outra sugestão seria buscar elucidar aspectos como a importância da atuação em outros 
mercados domésticos antes de adentrar mercados internacionais e a sua relação com a escolha dos modos de atuação. Além disso, trabalhos futuros podem ainda ser realizados visando identificar os fatores que contribuem para a continuidade das exportações e analisar a questão da escolha dos mercados externos de atuação.

\section{Referências}

ALEM, A. C.; CAVALCANTI, C. E. O BNDES e o Apoio à Internacionalização das Empresas Brasileiras. Revista do BNDES, Rio de Janeiro, v. 12, n. 24, p. 43-76, 2005.

ANDERSON, E.; WEITZ, B. The use of pledges to build and sustain commitment in distribution channels. Journal of Marketing Research, Chicago, v. 29, n. 1, p. 18-34, 1992.

ANDERSEN, O. On the internationalization process of firms: A critical analysis. Journal of International Business Studies, New York, v. 24, n. 2, p. 209-232, 1993.

BARNEY, J. B., Gaining and Sustaining Competitive Advantage. New Jersey: Prentice-Hall, 2011.

BARKEMA, H. G., BELL, J. H. J.; PENNINGS, J. M. Foreign entry, cultural barriers, and learning. Strategic Management Journal, Chicago, v. 17, n. 2, p. 151-166, 1996.

BARROS, I. S.. A implantação de uma modateca como fator de desenvolvimento para indústrias de moda do arranjo produtivo local do agreste pernambucano. Revista de Extensão da Universidade de Taubaté. Taubaté-SP, v. 2, n.1, p.1-12, 2009.

BAUER, M. W.; GASKELL, G. Pesquisa qualitativa com texto, imagem e som: um manual prático. 7. ed. Petrópolis - RJ: Vozes, 2008.

BEAMISH, P. W.; BANKS. J. C. Equity joint ventures and the theory of the multinational enterprise. Journal of International Business Studies, New York, v. 19, n. 2, p. 1-16, 1987. 
BENITO, G.; WELCH, L. De-internationalization. Management International Review, Wiesbaden, v.37, n. 2, p. 7-25, Special Issue, 1997.

BILKEY, W.; TESAR, G. The Export Behavior of Smaller Sized Wisconsin Manufacturing Firms, Journal of International Business Studies, New York, v. 8, n. 1, p. 93-98, 1997.

BUCKLEY, P. J.; CASSON, M. Models of the multinational enterprise. Journal of International Business Studies, New York, v. 29, n.1, p. 21-44, 1998.

CALOF, J.; BEAMISH, P. Adapting to foreign markets: explaining internationalization. International Business Review, New York, v. 4, n. 2, p. 115-31, 1995.

CAVUSGIL, S.T. Organizational characteristics associated with export activity. Journal of Management Studies. Malden, v. 21, n. 1. p. 3-22, 1984.

CHANG, S. J., International Expansion Strategy of Japanese Firms: Capability Building Through Sequential Entry, Academy of Management Journal, New York, v. 38, n. 2, p. 383-407, 1995. COVIELLO, N.; MUNRO, H. Network Relationships and the Internationalization Process of Small Software Firms, International Business Review, New York, v.6, n. 4, p. 361-386, 1997.

CRESWELL, J. W. W. Projeto de pesquisa. 2. ed. Porto Alegre: Bookman, 2010.

DAVIDSON, W. H. The Location of Foreign Direct Investment Activity: Country Characteristics and Experience Effects, Journal of International Business Studies, New York, v. 2, n. 2, p. 9-22, 1980.

DENZIN, N. K.; LINCOLN, Y. Handbook Qualitative Research. Thousand Oaks-Califórnia: Sage, 2005.

ERIKSSON, K. et al. Experiential knowledge and cost in the internationalization process. Journal of International Business Studies, New York, v. 28, n. 2, p. 337-360, 1997. 
FLICK, U. Uma introdução à pesquisa qualitativa. 3a ed. Porto Alegre: Bookman, 2009.

FORSGREN, M., "The Concept of Learning in the Uppsala Internationalization Process Model: A Critical Review", International Business Review, New York, v. 1, n. 3, p. 257-278, 2002.

FREITAS, E. M. S., RUPOLO, M.,; OLIVEIRA, B. R. B. Processo de internacionalização de uma empresa do Vale do São Francisco: Influência dos agentes externos e das escolhas gerenciais. Revista Organicom, São Paulo, v. 11, n. 21, p. 144-163, jan./abr. 2014.

HALLEN, L., JOHANSON, J.; MOHAMED, N. S. Interfirm adaptation in business relationships. Journal of Marketing, Chicago, v. 55, n. 2, p. 29-37, Apr. 1991.

HAVILA, V., JOHANSON, J.; THILENIUS, P. International businessrelationship triads, International Marketing Review, West Yorkshire, v. 21, n. 2, p. 172-186, 2004.

HILAL, A.; HEMAIS, C. A. Da Escola de Uppsala à Escola Nórdica de Negócios Internacionais: uma Revisão Analítica. In: ENCONTRO ANUAL DA ASSOCIAÇÃO NACIONAL DOS PROGRAMAS DE PÓSGRADUAÇÃO EM ADMINISTRAÇÃO, 30., 2001. Rio de Janeiro. Anais..., Rio de Janeiro: ANPAD, 2001, p. 1-14.

HITT, M. A., FRANKLIN, V.; ZHU, H. Culture, institutions and international strategy. Journal of International Management, Philadelphia, v.12, n. 2, p. 222-234, Jun. 2006.

HOLM, D. B., ERIKSSON, K.; JOHANSON, J. Business Networks and Cooperation in International Business Relationships. Journal of International Business Studies, New York, v. 27, n. 5, p.1033-1053, 1996.

HOLM, D. B., ERIKSSON, K.; JOHANSON, J. Creating Value through Mutual Commitment to Business Network Relationships. Strategic Management Journal, Chicago, v.20, n.5, p. 467-486, May. 1996. 
INSTITUTO BRASILEIRO DE GEOGRAFIA E ESTATÍSTICA - IBGE. Disponível em: <http://www.ibge.gov.br>. Acesso em: 09 mar. 2015. JOHANSON, J MATTSSON, L. Internationalisation in industrial systems: a network approach. London: Palgrave Macmillan UK, 2015.

JOHANSON, J.; WIEDERSHEIM-PAUL, F. The internationalization of the firm: Four Swedish cases. Journal of Management Studies, Malden, v. 12, n. 3, p. 305-322, 1975.

JOHANSON, J.; VAHLNE J. E. The Mechanism of Internationalization. International Marketing Review, West Yorkshire, v. 7, n. 4, p. 11-24, 1990.

JOHANSON, J.; VAHLNE J. E. The internationalization process of the firm: a model of knowledge development and increasing foreign commitments. Journal of International Business Studies, New York, v. 8, n. 1, p. 23-32, 1977.

JOHANSON, J.; VAHLNE J. E. Business relationship commitment and learning in the internationalization process. Journal of International Business Studies, New York, v. 1, n. 1, p. 83-101, 2003.

JOHANSON, J.; VAHLNE J. E. Commitment and opportunity development in the internationalization process: A note on the Uppsala internationalization process model. Management International Review, Wiesbaden, v. 46, n. 2, p.1-14, 2006.

JOHANSON, J.; VAHLNE J. E. The Uppsala internationalization process model revisited-from liability of foreignness to liability of "Outsidership". Journal of International Business Studies, New York, v. 40, n. 9, p. 1411-1431, 2009.

KOVACS, E. P.; MORAES, W. F. A. Modos de entrada e teorias de internacionalização: uma análise crítica. In: ASAMBLEA ANUAL DE CLADEA, 40, 2005. Santiago de Chile. Anais... Santiago de Chile: CLADEA, 2005. p. 1-15. 
KOGUT, B.; SINGH, H. The effect of national culture on the choice of entry mode. Journal of International Business Studies, New York, v. 19, n. 3, p. 411-32, 1988.

LINDQVIST, M. Infant multinationals: the internationalization of young, technology-based Swedish firms. Stockholm: Stockholm School of Economics Press, 1991.

MADHOK, A. Revisiting multinational firms' tolerance for joint ventures: A trust-based approach. Journal of International Business Studies, New York, v. 26, n. 1, p. 345-369, 1995.

MARTINS, G. A. Estudo de caso: uma estratégia de pesquisa. São Paulo: Atlas, 2008.

MARTINS; M .F., ANDRADE; E. O,; CANDIDO, G. A. Caracterização e contribuição das redes informacionais para o desenvolvimento dos arranjos produtivos locais no setor de confecções do agreste pernambucano. Revista Eletrônica de Gestão Organizacional, Recife, v. 7, n .1, p. 27-46, Jan/Abr. 2009.

MATOS; K. S. L.; VIEIRA, S. L. Pesquisa educacional. Fortaleza: UECE, 2001.

MCDOUGALL, P. P. International Versus Domestic Entrepreneurship: New venture strategic behavior and industry structure. Journal of Business Venturing, Bloomington, v.4, n. 6, p.387-400, Nov. 1989.

MELIN, L. Internationalization as a strategy process. Strategic Management Journal, Chicago, v. 13, n. S2, p. 99-118, Winter 1992.

MERRIAM, S. B. Qualitative research and case study applications in education. San Francisco: Jossey-Bass, 2009.

MINISTÉRIO DA INDÚSTRIA E COMÉRCIO EXTERIOR - MDIC. Disponível em: <http://www.mdic.gov.br>. Acesso em: 20 mar. 2016.

PATTON, M. Qualitative research and evaluation methods. Thousand Oaks- California: Sage, 2001. 
PEDERSEN, T.; PETERSEN, B. Explaining gradually increasing resource commitment to a foreign market. International Business Review, New York, v. 7, n. 5, p. 483-501, Oct. 1998.

PETTIGREW, A. M. Longitudinal field research on change: Theory and practice. Organization Science, Hanover, v.1, n. 3, p.267-292, 1990.

PETTIGREW, A. M. The double hurdles of management research. In: CLARKE, T, (ed.). Advancement in Organizational Behaviour. London: Dartmouth Press, 1997. p. 277-296.

SCHWEIZER, R., VAHLNE J.E.; JOHANSON, J. Internationalization as an entrepreneurial process. Journal International Entrepreneurship, Netherlands, v. 8, n. 4, p. 343-370, 2010.

SERVIÇO BRASILEIRO DE APOIO ÀS MICRO E PEQUENAS EMPRESAS - SEBRAE. Disponível em: http:<//www.sebrae.com.br>. Acesso em: 10 mar. 2012.

SHARMA, D. D.; JOHANSON, J. Technical consultancy in internationalization. International Marketing Review, West Yorkshire, v. 4, n. 4, p. 20-29, 1987.

SOUSA, L. L.; FREITAS, L. S. Mudanças estratégicas e recursos organizacionais: um estudo de caso numa indústria de papéis sanitários. In: EMPREENDEDORISMO E PEQUENAS EMPRESAS, 7., 2012. Anais..., Florianópolis - SC: ANEGEPE, 2012. p. 1-11.

STAKE, R. E. A arte da investigação com estudos de caso. Coimbra: Fundação Gulhenkian, 2009.

SEBRAE. Estudo econômico do arranjo produtivo local de confecções do agreste pernambucano, 2013. Acesso em: <http://www.sebrae.com. br>. Acesso em: 30 abr. 2016.

WELCH, L. S.; LUOSTARINEN, R. Internationalization: Evolution of a concept. Journal of General Management, Oxford, v. 17, n. 3, p. 333-334, 1988. 
WIEDERSHEIM-PAUL, F., OLSEN, H.-C.; WELCH, L. S. Preexport activity: The first step in internationalization. Journal of International Business Studies, New York, v. 8, n. 1, p. 47-58, 1978.

XAVEIR, A. Edição Especial Pernambuco Economia e Perspectivas. Revista Veja, ed. 2476, ano 49, n. 18, maio de 2016.

Data de Submissão: 24/06/16

Data de Aprovação: 29/08/16 